\title{
Head circumference - a useful single parameter for skull volume development in cranial growth analysis?
}

\author{
Markus Martini ${ }^{1,4^{*}}$ D, Anne Klausing ${ }^{1}$, Guido Lüchters ${ }^{2}$, Nils Heim and Martina Messing-Jünger ${ }^{3}$
}

\begin{abstract}
Background: The measurement of maximal head circumference is a standard procedure in the examination of childrens' cranial growth and brain development. The objective of the study was to evaluate the validity of maximal head circumference to cranial volume in the first year of life using a new method which includes ear-to-ear over the head distance and maximal cranial length measurement.

Methods: 3D surface scans for cranial volume assessment were conducted in this method comparison study of 44 healthy Caucasian children (29 male, 15 female) at the ages of 4 and 12 months.

Results: Cranial volume increased from measurements made at 4 months to 12 months of age by an average of $1174 \pm 106$ to $1579 \pm 79 \mathrm{ml}$. Maximal cranial circumference increased from $43.4 \pm 9 \mathrm{~cm}$ to $46.9 \pm 7 \mathrm{~cm}$ and the ear-to ear measurement increased from $26.3 \pm 21 \mathrm{~cm}$ to $31.6 \pm 18 \mathrm{~cm}$ at the same time points. There was a monotone association between maximal head circumference $(\mathrm{HC})$ and increase in volume, yet a backwards inference from maximal circumference to the volume had a predictive value of only $78 \%$ (adjusted $R^{2}$ ). Including the additional measurement of distance from ear to ear strengthened the ability of the model to predict the true value attained to $90 \%$. The addition of the parameter skull length appeared to be negligible.

Conclusion: The results demonstrate that for a distinct improvement in the evaluation of a physiological cranial volume development, the additional measurement of the ear-to ear distance using a measuring tape is expedient, and, especially for cases with pathological skull changes, such as craniosynostosis, ought to be conducted.
\end{abstract}

Keywords: Head circumference, Validity, Ear-to-ear measurement, Skull volume, 3d scan, Cranial growth

\section{Background}

The measurement of maximal head circumference $([\mathrm{HC}]$ or occipito-frontal circumference $[\mathrm{OFC}]$ ) has been a standard procedure in the examination of childrens' cranial growth and brain development for decades [1-4]. It is a quick, simple and economic screening method without the danger of exposure to radiation. Early detection of pathological changes are ascertained with this method. Normative data for pediatric cranial circumference and braincase volume are of multidisciplinary

\footnotetext{
*Correspondence: markus.martini@ukbonn.de; markus.martini@ukb.unibonn.de

${ }^{1}$ Department of Maxillofacial and Plastic Surgery, University of Bonn, Sigmund-Freud Str. 25, 53127 Bonn, Germany

${ }^{4}$ Department of Oral, Maxillofacial and Plastic Surgery, University of Bonn, Welschnonnenstraße 17, D - 53111 Bonn, Germany

Full list of author information is available at the end of the article
}

interest. In addition to its primary importance for differential diagnosis and therapy decisions for neurosurgical, maxillofacial- and plastic surgery, $[5,6]$, as well as for anthropological study of evolution $[7,8]$, these measurements are of immense importance to pediatric doctors and neurologists [9-13]. The collection of exact cranial volume data and anthropometric parameters is, for this reason, the subject of countless studies [14-19]. Improvements in cranial volume measurement methods rely increasingly on $3 \mathrm{D}$ databases. This type of data acquisition can occur in a semi-automatic manner using CT [20-22] or MRT segmentation, or, most recently, via $3 \mathrm{D}$ photography in combination with traditional methods of measurement [18, 23-25].

The goal of this study was to examine whether head circumference measurement alone is a good predictor of 
cranial volume, and whether the addition of head length and head height measurements increase the predictability of skull volume. Such additional measures included the ear-to-ear distance over the vertex to be measured for the skull height calculation as well as the head length over the top of the head point. Since cranial growth in the time between birth and the 12th month of life is the strongest [5], this evaluation focused on this period.

\section{Methods}

Approval for the study was obtained from the local Ethic Committee of the Medicine faculty of the University of Bonn. The study was performed at the Department of Maxillofacial and Plastic Surgery at the University of Bonn and 44 healthy 4-month-old Caucasian children (29 male, 15 female) who had an unremarkable general medical history, normal course of pregnancy and unremarkable head form were included. Assessments were conducted between the ages of 4 months and 12 months from 2014 to 2016 and included a single 3D optical image scan of every child's head without follow up.

First, 3D optical image scans of the cranium and facial surface, with the help of an optical 3D sensor (3D-Shape ${ }^{\oplus}$, Erlangen, Deutschland). These data were triangulated and fused using Software Slim3D (3D-Shape ${ }^{\circ}$ Erlangen, Deutschland). After converting to a STL- format, cephalometric analysis of the data followed with the help of Software Onyx $\mathrm{Ceph}^{\mathrm{\tau m}}$ (Image Instruments $\mathrm{GmbH}$, Chemnitz, Deutschland). Several reference parameters were identified for each patient's cranium using Onyx $\mathrm{Ceph}^{\mathrm{TM}}$ including: three medians (Glabella [Gl], Opistocranion [Oc], the point at the top of the head $[\mathrm{ToH}])$, and two bilateral (Preauricular $[\mathrm{Pa}]$, Infraorbital [Or]) soft tissue reference points. The Preauricular and Infraorbital points defined the horizontal plane $(\mathrm{H})$, in accordance with the commonly used Frankfort horizontal plane.

After generation of the 3D data set and voxelization, intracranial volume was calculated based on the total sum of all voxels located within the space between the vertex and the angularized cranial base plane $(\mathrm{H})$.

Beside the maximal head circumference (HC) the cranial length (CL) from glabella to opistocranion (Gl-ToH-Oc) and the cranial height $(\mathrm{CH})$, measured from cranial ear base to ear base on the contralateral side (Pa-ToH-Pa = ear-to-ear measurement; EtEm; Fig. 1) were determined using the software Onyx Ceph. Regarding the sample size the suggestion of Babyak and Rothman were followed by taking 10 to 15 observations per predictor variable $(\mathrm{HC}, \mathrm{CL}, \mathrm{CH})$ to avoid overfitting in a multiple regression i.e. a too heavy influence by random error in the data [26, 27]. Statistical analysis was conducted using STATA 14.2 (College Station, Texas, USA), which included Pearson correlation, multiple linear regression, likelihood

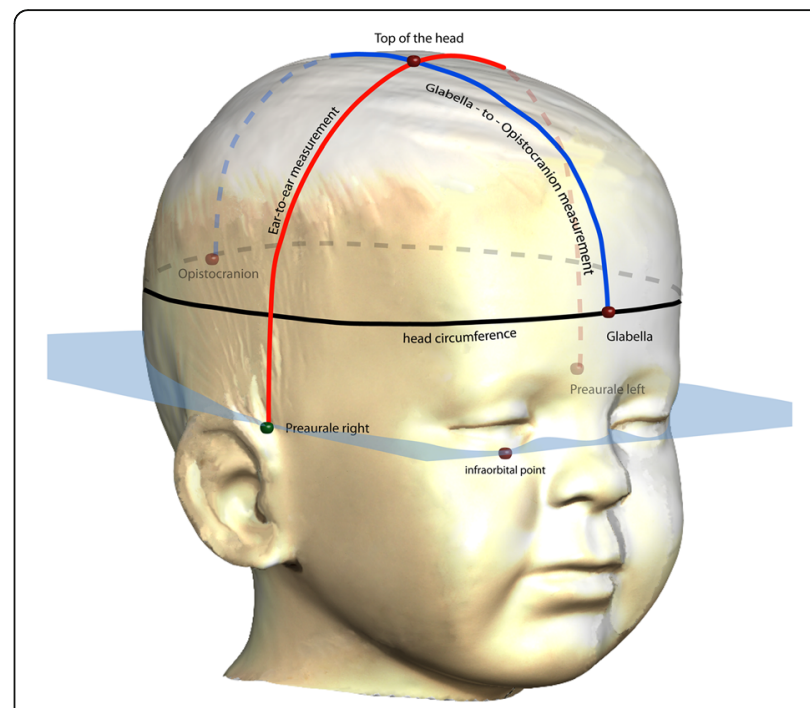

Fig. 1 3D scan - Ear-to-ear measurement $(\mathrm{CH})$, maximal head circumference $(\mathrm{HC})$ and glabella-to-opistocranion measurement $(\mathrm{CL})$

ratio tests, and Bland-Altman plots. Means and standard deviations are given and effect sizes are reported as partial eta ${ }^{2}$.

\section{Results}

The average cranial volume for all children during the course of this study expanded from $1174 \pm 106 \mathrm{ml}$ (4 months) to $1579 \pm 79 \mathrm{ml}$ (12 months). The average intracranial volume growth among the 29 boys (1351 \pm $155 \mathrm{ml}$ ) was larger than that of the 15 girls (1213 \pm $113 \mathrm{ml}$ ). In the same period, maximum cranial circumference increased from $43.4 \pm 9 \mathrm{~cm}$ to $46.9 \pm 7 \mathrm{~cm}$, the cranial length increased from $23.6 \pm 13 \mathrm{~cm}$ to $25.3 \pm$ $13 \mathrm{~cm}$ and the ear-to-ear measurement increased from $26.3 \pm 21 \mathrm{~cm}$ to $31.6 \pm 18 \mathrm{~cm}$ (Fig. 2). The maximal cranial circumference and measured volumes showed statistically significant linear correlations across all children (Pearson $r=0.8828 ; p=0.000$ ). For any given cranial circumference, $78 \%\left(R^{2}\right)$ of the volume variability was explained by the model (Fig. 3 ).

To examine the question of whether the predictiveness can be improved by the addition of further parameters, various models were compared. It was assumed that cranial volume at the base of the skull approximates the volume of a half ellipsoid. Hence, a spherical volume calculation was made based on the ear-to-ear measurements as well as the length-girth measurement, analogue to earlier studies [28-30]. The mathematically determined cranial volumes using $\mathrm{HC}, \mathrm{CL}$ and $\mathrm{CH}$ were compared with the voxel-based cranial volume calculation made by the software program OnyxCeph using Bland-Altman plots. These showed no clear differences in the degree of agreement of the cranial volumes 

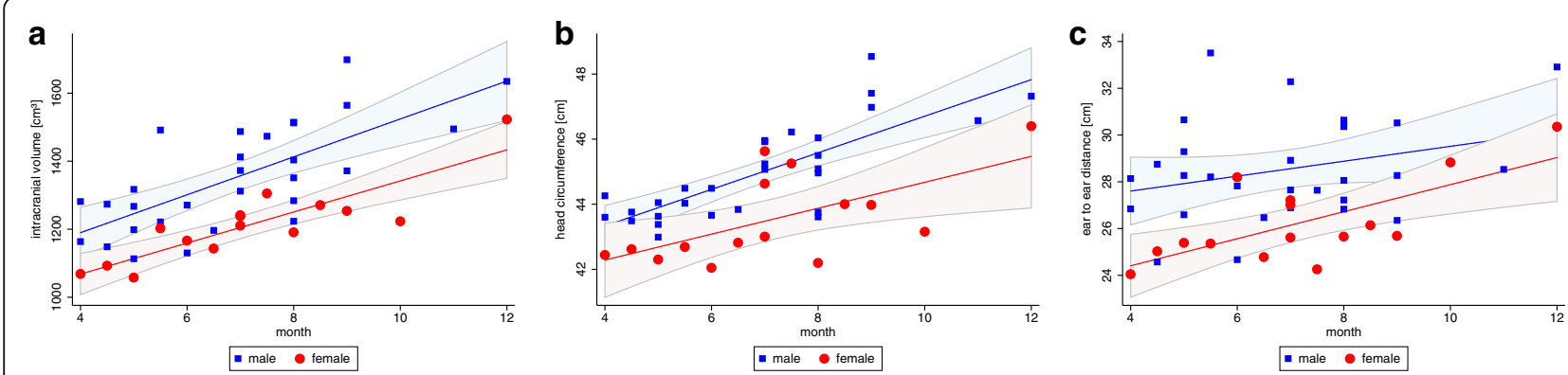

Fig. 2 Cranial growth development in the first year of life for the parameters $\mathbf{a}$ ) intracranial volume, b) head circumference (HC) and c) cranial height (CH, ear-to ear measurement over top of the head). Linear regression and 95\% Confidence Intervals for girls and boys

between the two measurement methods. Variabilities using the two methods were also equivalently large.

Next, the predictiveness of three different multiple linear regression models were compared. First, Model A included head circumference $(\mathrm{HC})$, cranial height $(\mathrm{CH})$ and cranial length (CL). This model achieved highly accurate volume correspondence of $90 \%$ (adjusted $\mathrm{R}^{2}$ ). The average variance inflation factor (VIF) of 1.5 (range 1.4-1.7) eliminated the issue of collinearity. Statistically significant effects were shown for the predictors maximal circumference $(p=0.000)$ and ear-to-ear distance $(p=0.000)$. Cranial length (Gl-ToH-O), however, showed no statistically significant effect $(p=0.907)$. After a z-transformation, the maximal cranial circumference proved to be the most influential variable (beta $=0.69$ ), followed by cranial height (beta $=0.40$ ) and cranial length (beta $=-0.007$ ). This was also reflected by the differences in effect size quantified as partial eta ${ }^{2}$ (HC: 74\%; CH: 54\%; CL: 0.03\%;).

Further, a reduced model based on head circumference and cranial height (Model $\mathrm{B}$ : $\mathrm{HC}$ and $\mathrm{CH}$ ), was compared to Model A ( $\mathrm{HC}, \mathrm{CH}$ and $\mathrm{CL}$ ) using a likelihood ratio test. This yielded no significant difference in predictiveness of calculated volume (B vs. A, LR: $p=0.902$ ).

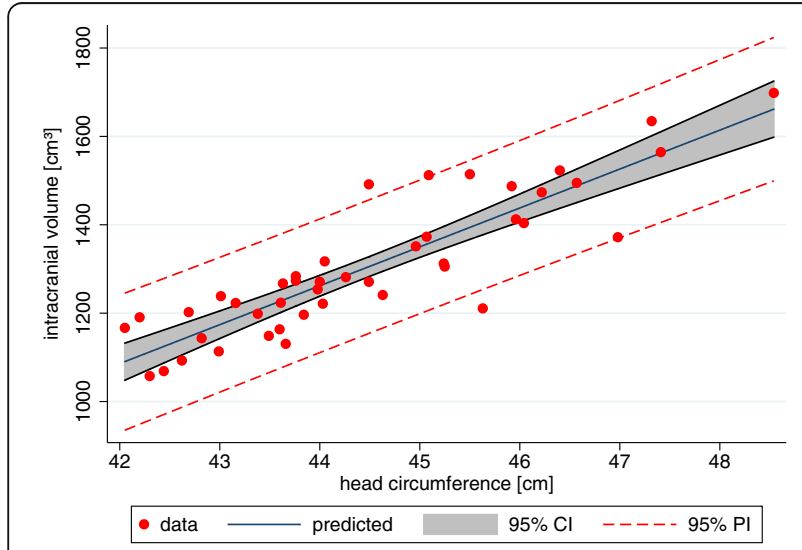

Fig. 3 Head circumference (HC) and head volume; 95\% Confidence Interval and 95\% Prediction Interval
Hence, the addition of CL had no effect on predictive value. Sex was then added as a predictor (Model C: $\mathrm{HC}$, $\mathrm{CH}$, Sex), which, in turn, rendered no increase in explanatory power (B vs. C, LR: $p=0.135$ ). Figure 4 and Table 1 moreover show that estimated coefficients did not significantly differ in the two models. According to the principle of parsimony (Occam's razor), Model B with the variables head circumference and ear-to-ear measurement should be preferred, since both Model A and $\mathrm{B}$ had an adjusted $\mathrm{R}^{2}$ von $90 \%$ (Table 1 ).

To calculate the expected cranial volume with a given $\mathrm{HC}$ and $\mathrm{CL}$, coefficients and absolute terms were derived from linear regression model and transferred to the formula as follows: Vol. $(\mathrm{cm} 3) \hat{=} 68 \cdot \mathrm{HC}+27 \cdot \mathrm{CL}-2472$.

\section{Discussion}

In the first 2 years of life the infant skull experiences its greatest structural and geometric change [31]. Intracranial volume doubles during the first 6-9 months of life [5], and increases by another $20 \%$ in the subsequent 6 months

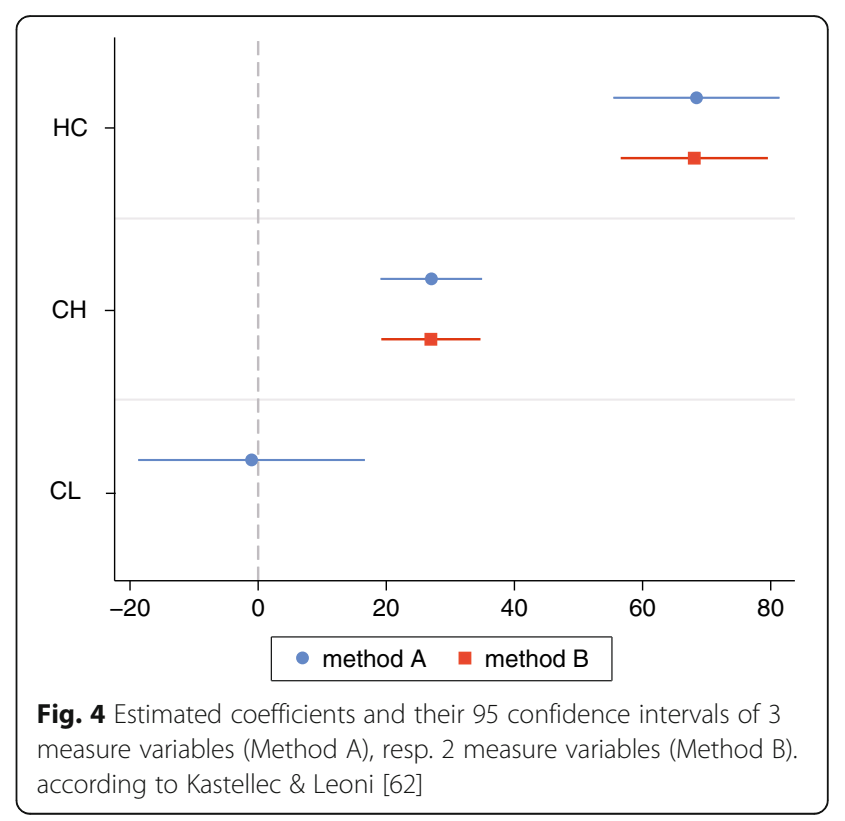


Table 1 Impact of 3 measure variables (Method A: head circumference $[\mathrm{HC}]$, cranial height $[\mathrm{CH}]$, cranial length $[\mathrm{CL}], 2$ measure variables (Method B: $\mathrm{HC}, \mathrm{CH}$ ) and with added gender and age (Method C); n.s. not significant; ${ }^{*} p<0.05 ;{ }^{* *} p<0.01$; ${ }^{* * *} p<$ 0.001

\begin{tabular}{llll}
\hline Variable & Method A & Method B & Method C \\
\hline $\mathrm{HC}$ & $68.40^{* * *}$ & $68.07^{* * *}$ & $70.25^{* * *}$ \\
$\mathrm{CH}$ & $27.03^{* * *}$ & $26.96^{* * *}$ & $28.86^{* * *}$ \\
$\mathrm{CL}$ & -1.03 n.s. & & \\
sex & & & -26.87 n.S. \\
Intercept & $-2463.02^{* * *}$ & $-2471.68^{* * *}$ & $-2603.73^{* * *}$ \\
adj. $\mathrm{R}^{2}$ & 0.89 & 0.90 & 0.90 \\
\hline
\end{tabular}

[5]. A significant positive correlation between brain volume and cranial circumference has been demonstrated by postmortem studies and CT examinations of deceased newborns [32, 33], in line with MRI studies of older children [4]. For this reason, the head circumference measure $(\mathrm{HC})$ is a recognized, well-established screening parameter for intracranial volume [34-36]. This measure should, however, not be accepted without reservation, since maximal head circumference primarily reflects expansion of the base of the skull [22, 29, 37, 38].

Estimating skull volume is based, on the one hand, on country-specific $\mathrm{HC}$ growth reference charts, which are periodically updated $[10,13]$. On the other, a wide variety of specific craniometric ratios attempt to estimate the change in skull volume and make allowances for brain configuration $[29,39]$. Further, early on Buda et al. [37] pointed out that the $\mathrm{HC}$ in children with nonnormally shaped skulls is not a valid indicator of cranial volume [37]. Skull morphology appears too complex to be represented via any single parameter, according to Marcus et al. [21], in contrast to Rijken [40]. Our own examinations of healthy children showed invalidity in the relation between $\mathrm{HC}$ and cranial volume (Fig. 3). The relationship was monotonously linear, yet it was not completely reliable, and showed small skull volumes for large HCs and vice versa, in line with Treit [11]. This can not be explained merely by sex-specific differences in skull form in which girls have shorter and broader skulls compared to boys [29]. At the end of the exponential skull growth phase at the age of 2 years up to the 6th year of life, the attained HC gained high reliability with $r=0.93$ according to Rollins [10], a reliability that is reached in this study only after the addition of two further parameters (cranial height and length) for the age range 4-12 months.

Likewise, as mentioned above, the lack of validity of maximal head circumference for estimating skull volume is problematic when referencing norm values, regardless of which pathological group is used for comparison. One problem for intracranial volume determination is the lack of adequate reference material and normative ageand sex-adapted control groups based on the same evaluation procedures [41]. Even now, the most commonly referenced skull volume estimation method dates from the early 1960s which utilizes a two-dimensional radiological dataset and mathematical calculations based on the assumption of a proximal spherical volumetric relationship to estimate skull volume [42]. This estimation technique has found application by numerous authors [22, 28, 29, 38, 43] and including additional usage of a multiplier for $2 \mathrm{D}$ radiographic pictures [37, 42, 44]. However, the reliability 2D skull image evaluation is very limited due to inadequate reproducibility [45-47] and this method is not commensurate with modern standards of analysis. Moreover aside from country-specific living standards [13] cohort analyses show that the average $\mathrm{HC}$ is larger now than it was 50 years ago $[29,48]$. Hence, a current comparison of $\mathrm{HC}$ in the literature with volume data that are even additional 10 years older warrants, at the very least, an age correction. Generally the reference data are based on segmentation of CT or MRI scans [5, 11, 14, 22] or 3D optical surface scans of healthy children [24, 25, 49]. Based on these findings, a critical debate followed regarding older publications [22, 50-52]. Recently Tenhagen [53] and Van Lindert et al. [54] compared these three different techniques and endorsed the optical 3D scan method due to its many advantages.

Intracranial volume calculation based on CT-scans uses the Cavalieri principle: the cranial volume is calculated as the sum of the surface products taking into account the CT layer thickness cranial of the foramen magnum to the vertex $[5,14,15,23,41,55]$. The axial layers in sequential CTs are generally aligned with the osseous frontobase and are, therefore, valid for intracranial volume detection. Modern spiral CTs even allow a multiplanar reconstruction with free $\mathrm{H}$-plane referencing. Analysis software for modern 3D photogrammetry also enables free angulation of the caudal layers for volume calculations from the sum of the individual volume elements between the triangle network of the Vertex - surface data set and the specified cranial base layer (Fig. 5).

Thus, 3D photogrammetry as employed by MeyerMarcotty et al. (analogous to MRI examinations by Tenhagen, [53]) used a caudal bounded layer through the reference points of both tragi and nasion to calculate normal volume [24]. In contrast, Seeberger [25] set this further caudal under the nose, defined via the subnasal point. Tenhagen's intention in using a steep angle of the layer was to account for the specialness of occipital bossing in patients with scaphocephaly. They rejected the widely recognized Frankfort horizontal plane in favor of the nasion as a reference point, as Acer et al. did as 


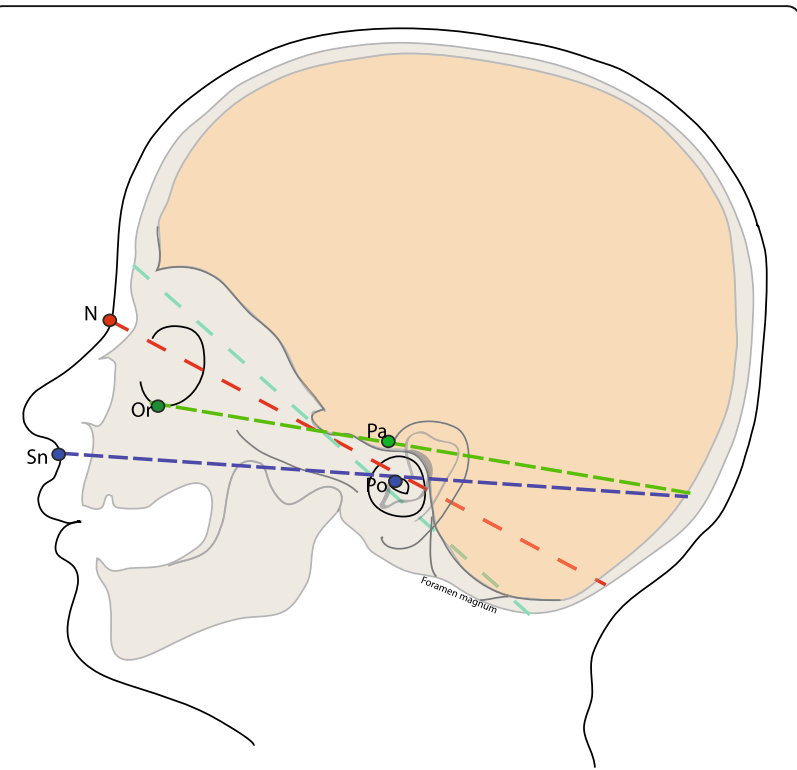

Fig. 5 Infant cranium laterally with different h-plane angulations. $\mathrm{N}=$ nasion, $\mathrm{Sn}=$ subnasal, $\mathrm{Or}=$ Infra-orbitalpoint, $\mathrm{Po}=$ Porion; $\mathrm{Pa}=$ Preaural; green line - Frankfort Horizontal plane

well [15]. In selecting the subnasal point as a reference instead of the nasion, it should be taken into consideration that the intracranial volume estimates take large parts of the mid-face into account. Hence, Seeberger's values are commensurately larger than those of Meyer-Marcotty et al. (with $100.32 \mathrm{~cm}^{3}$ at the age of 6 months and $112.05 \mathrm{~cm}^{3}$ at the age of 12 months). It can be problematic that, depending on the quality of the 3D laser scan image, the tragus point may be difficult to identify. In this study, therefore, the preaural point was chosen instead to define the Frankfort horizontal plane, since it is consistently easy to identify the cranial base of the ear as a reference point, and easily measurable with a tape measure for clinical examinations. Generally, the fact that the precision of the validity of the intracranial volume varies depending on the selected layer and the individual inclination of the skull base should be considered.

3D photography and CT-analysis were combined by Toma et al. [23] in their skull form analysis in children with scaphocephaly. In addition to the Cavalieri principle for volume calculation, a lot-based cranial height measurement (auricular head height: Vertex to Frankfort horizontal plane) was also used, among others parameters, to distinguish pathology from normal. As the authors point out with regret within the text of their article, such a comparison was not possible for cranial height for lack of norm values. This absence of data is due, on the one hand, to the danger of radiation exposure during CT scan for subjects, which also renders this method inappropriate for routine measurement.
On the other hand, there is also limited availability of special cephalometric measurement devices. In the clinical context, quantification of cranial measures is conducted with such instruments such as a craniometer, head spanner or anthropometric calipers. With the help of a craniometer, maximal cranial length (glabella-opistocranion) and maximal cranial width (euryon-euryon) measured through the head-center can be directly measured and the cranial volume can be determined $[28,56]$. Indices such as the auricular head height via head spanner or cranial width [57] and cranial height measurements $[39,58]$ with the help of the spreading caliper of Hrdlička are only available in special centers and norm values with sufficiently large samples are hardly possible to generate.

Further, the possibility of 3D photocephalometry is not available to every investigator. As this study based on 3D surface scanning shows, just using a tape measure to measure to parameters enables calculation of a good approximation to the true intracranial volume. The method introduced here attained the same correlation factor (0.91) as that of 3D Photogrammetry with CT [59]. The volumes measured in this study concurred with those of the 3D surface-scan studies of MeyerMarcotty and Seeberger regarding the 6 and 12-month evaluations of Caucasian children (see Table 2). These volumes were, however, distinctly above those of the CT based investigations by Toma [23], Abbott [14] and Sgouros [22]. The ear-to-ear measurements as well as the HC-measurements were, on the whole, slightly larger than those reported in Hou et al. for one-year-old Chinese children with $48 \mathrm{~cm}$ versus $47 \mathrm{~cm}$ and $33 \mathrm{~cm}$ versus $27 \mathrm{~cm}$, respectively [60], whereby the $\mathrm{HC}$ data in this study corresponded to the percentile curves of German children in the normal range.

The visual imaging-based measurement methods a) cranial height in the form of ear-to-ear distance over the vertex, as well as b) the cranial length, measured as the distance from glabella to external occipital protuberance over the Vertex, which have been described in the literature $[60,61]$, were examined here for their validity with regard to volume calculation. The use of these measures ( $\mathrm{CH}$ and $\mathrm{CL}$ ) in addition to $\mathrm{HC}$ assessed with a measuring tape, decisively raise the predictive power of cranial volume of the children in the first year of life from $78 \%$ to $90 \%$, whereby the ear-to-ear measurement is of particular relevance. This is independent of age or sex (Table 1). Hence, in daily clinical practice the predictive value of $\mathrm{HC}$ and $\mathrm{CH}$ are sufficiently high. Dolichocephalic and turicephalic head shapes can also be detected quickly, easily and validly in children with putatively normal skull shapes merely using a measuring tape, and the skull shape can be specified quantitatively as well. As far as we know, this is the first demonstration of the 
Table 2 Volume measurement ( $\mathrm{ml}$ ) according to age 1 (6 months) and age 2 (12 months), relevant sample size and imaging method. In case that only graphics were presented instead of numerical values, the figures were reconstructed from these graphics using the software Digitizelt 2.2 (Braunschweig, Germany; Table 2)

\begin{tabular}{|c|c|c|c|c|c|c|c|}
\hline & Imaging Method & Number & Age 1 & Volume & Number & Age 2 & Volume \\
\hline Treit 2016 [11] & MRT & 15 & $6 \pm 1$ & $1145 \pm 113$ & 22 & $12 \pm 1$ & $1239 \pm 112$ \\
\hline Lichtenberg 1960 [42] & X-ray & & $7 \pm 1$ & $920 \pm 136$ & & $10 \pm 1$ & $990 \pm 118$ \\
\hline Toma 2010 [23] & $\mathrm{CT}$ & & $5-6$ & 799 & & $11 \pm 2$ & 997 \\
\hline Abbott 2000 [14] & CT & 63 & $6 \pm 1$ & $853 \pm 134$ & & $12 \pm 1$ & $1079 \pm 72$ \\
\hline Sgouros 1999 [22] & $\mathrm{CT}$ & & $6 \pm 1$ & $829 \pm 104$ & & $12 \pm 1$ & $1026 \pm 52$ \\
\hline Meyer-Marcotty 2014 [24] & 3D-Scan & 52 & $6 \pm 0.5$ & $1229 \pm 100$ & 52 & $12 \pm 0.5$ & $1460 \pm 112$ \\
\hline This study 2017 & 3D-Scan & 8 & $6 \pm 0.5$ & $1228 \pm 116$ & 3 & $12 \pm 0.5$ & $1551 \pm 74$ \\
\hline Seeberger 2016 [25] & 3D-Scan & 246 & $0-6$ & $1336 \pm 207$ & 301 & $7-12$ & $1527 \pm 168$ \\
\hline
\end{tabular}

relationship between volume and measuring tape measurements.

There are several limitations inherent in our study. The database of this study with 44 children ranging in age from 4 to 12 months is too small to derive normative data, and requires a more extensive investigation. In addition, in as much as further studies are based on 3D photography, which reference planes should be used to optimally determine the approximate true intracranial volume needs to be explored. On the whole, the scanbased volume estimates are necessarily larger than those of real intracranial volumes, since they include in the thickness of skin, hair, cranial vault and cerebrospinal fluid space: These estimates, therefore, must lie above estimates any based on CT and autopsy findings.

\section{Conclusion}

These results demonstrate that a clear improvement is made to the assessment of a physiological cranial volume development in children up to 12 months by the mere addition of ear-to-ear distance by means of a measuring tape, in addition to the HC. This is particularly useful for detecting pathological cranial changes as in microor macrocephaly or for more complex conditions, such as craniosynostoses.

\section{Abbreviations}

CH: Cranial height; CL: Cranial length; Gl: Glabella; H: Horizontal plane; HC: Maximal head circumference,; Oc: Opistocranion; OFC: Occipito-frontal circumference; Or: Infraorbital; Pa: Preauricular; ToH: Top of the head; VIF: Variance inflation factor

\section{Acknowledgements}

Not applicable.

\section{Funding}

Not applicable: Neither the authors nor the institutions received third party funding associated with the study.

\section{Authors' contributions}

MM conceived the study, carried out design and coordination and wrote the manuscript, AK and $\mathrm{NH}$ collected and evaluated the data, GL performed the statistical analysis, MMJ participated in acquisition of the patients and data collection. All authors read and approved the final manuscript.

\section{Ethics approval and consent to participate}

The study was conducted and approved following the regulations of the local Ethic Committee of the Medicine faculty of the University of Bonn. The study was registered as No. 189/17.

\section{Consent for publication}

Not applicable.

\section{Competing interests}

The authors declare that they have no competing interests or commercial associations that might post a conflict of interest in connection with the submitted article.

\section{Publisher's Note}

Springer Nature remains neutral with regard to jurisdictional claims in published maps and institutional affiliations.

\section{Author details}

${ }^{1}$ Department of Maxillofacial and Plastic Surgery, University of Bonn, Sigmund-Freud Str. 25, 53127 Bonn, Germany. ${ }^{2}$ Center for Development Research (ZEF), University of Bonn, Walter-Flex-Str. 3, 53113 Bonn, Germany. ${ }^{3}$ Department of Neurosurgery, Asklepios Children's Hospital, Arnold-Janssen-Str. 29, 53757 Sankt Augustin, Germany. ${ }^{4}$ Department of Oral, Maxillofacial and Plastic Surgery, University of Bonn, Welschnonnenstraße 17, D - 53111 Bonn, Germany.

Received: 10 July 2017 Accepted: 22 December 2017

Published online: 10 January 2018

\section{References}

1. Gale CR, Walton S, Martyn CN. Foetal and postnatal head growth and risk of cognitive decline in old age. Brain. 2003;126:2273-8.

2. Bray PF, Shields WD, Wolcott GJ, Madsen JA. Occipitofrontal head circumference-an accurate measure of intracranial volume. J Pediatr. 1969; 75:303-5.

3. Vernon PA, Wickett JC, Bazana PG, Stelmack RM. The neuropsychology and psychophysiology of human intelligenc. In: Sternberg RJ, editor. Handbook of intelligence. Cambridge: Cambridge University Press; 2000. p. 245-64

4. Bartholomeusz HH, Courchesne E, Karns CM. Relationship between head circumference and brain volume in healthy normal toddlers, children, and adults. Neuropediatrics. 2002;33:239-41.

5. Kamdar MR, Gomez RA, Ascherman JA. Intracranial volumes in a large series of healthy children. Plast Reconstr Surg. 2009;124:2072-5. 
6. MacLullich AM, Ferguson KJ, Deary IJ, Seckl JR, Starr JM, Wardlaw JM. Intracranial capacity and brain volumes are associated with cognition in healthy elderly men. Neurology. 2002;59:169-74.

7. Falk D, Hildebolt C, Smith K, Morwood MJ, Sutikna T, Brown P, Jatmiko, Saptomo EW, Brunsden B, Prior F. The brain of LB1, Homo Floresiensis. Science. 2005;308:242-5.

8. Falk D, Hildebolt C, Smith K, Morwood MJ, Sutikna T, Jatmiko, Wayhu Saptomo E, Prior F. LB1's virtual endocast, microcephaly, and hominin brain evolution. J Hum Evol. 2009;57:597-607.

9. Ivanovic DM, Leiva BP, Perez HT, Olivares MG, Diaz NS, Urrutia MS, Almagia AF, Toro TD, Miller PT, Bosch EO, Larrain CG. Head size and intelligence, learning, nutritional status and brain development. Head, IQ, learning, nutrition and brain. Neuropsychologia. 2004;42:1118-31.

10. Rollins JD, Collins JS, Holden KR. United States head circumference growth reference charts: birth to 21 years. J Pediatr. 2010;156:907-13. 913 e901-902

11. Treit S, Zhou D, Chudley AE, Andrew G, Rasmussen C, Nikkel SM, Samdup D, Hanlon-Dearman A, Loock C, Beaulieu C. Relationships between head circumference, brain volume and cognition in children with prenatal alcohol exposure. PLoS One. 2016;11:e0150370.

12. van der Linden V, Pessoa A, Dobyns W, Barkovich AJ, Junior HV, Filho EL, Ribeiro EM, Leal MC, Coimbra PP, Aragao MF, et al. Description of 13 infants born during October 2015-January 2016 with congenital Zika virus infection without Microcephaly at birth - Brazil. MMWR Morb Mortal Wkly Rep. 2016; 65:1343-8.

13. von der Hagen M, Pivarcsi M, Liebe J, von Bernuth $H$, Didonato $N$ Hennermann JB, Buhrer C, Wieczorek D, Kaindl AM. Diagnostic approach to microcephaly in childhood: a two-center study and review of the literature. Dev Med Child Neurol. 2014;56:732-41.

14. Abbott AH, Netherway DJ, Niemann DB, Clark B, Yamamoto M, Cole J, Hanieh A, Moore MH, David DJ. CT-determined intracranial volume for a normal population. J Craniofac Surg. 2000;11:211-23.

15. Acer N, Sahin B, Bas O, Ertekin T, Usanmaz M. Comparison of three methods for the estimation of total intracranial volume: stereologic, planimetric, and anthropometric approaches. Ann Plast Surg. 2007:58:48-53.

16. Lee MC, Shim KW, Yun IS, Park EK, Kim YO. Correction of Sagittal Craniosynostosis using distraction Osteogenesis based on strategic categorization. Plast Reconstr Surg. 2017;139:157-69.

17. Heller JB, Heller MM, Knoll B, Gabbay JS, Duncan C, Persing JA. Intracranial volume and cephalic index outcomes for total calvarial reconstruction among nonsyndromic sagittal synostosis patients. Plast Reconstr Surg. 2008; 121:187-95.

18. Kyriakopoulou V, Vatansever D, Davidson A, Patkee P, Elkommos S, Chew A, Martinez-Biarge M, Hagberg B, Damodaram M, Allsop J, et al. Normative biometry of the fetal brain using magnetic resonance imaging. Brain Struct Funct. 2016. :https://doi.org/10.1007/s00429-016-1342-6.

19. Delye H, Clijmans T, Mommaerts MY, Sloten JV, Goffin J. Creating a normative database of age-specific 3D geometrical data, bone density, and bone thickness of the developing skull: a pilot study. J Neurosurg Pediatr. 2015:16:687-702.

20. Smith K, Politte D, Reiker G, Nolan TS, Hildebolt C, Mattson C, Tucker D, Prior F, Turovets S, Larson-Prior $\sqcup$. Automated measurement of skull circumference, cranial index, and braincase volume from pediatric computed tomography. Conf Proc IEEE Eng Med Biol Soc. 2013:2013:3977-80.

21. Marcus JR, Domeshek LF, Das R, Marshall S, Nightingale R, Stokes TH, Mukundan $\mathrm{S} \mathrm{Jr}$. Objective three-dimensional analysis of cranial morphology. Eplasty. 2008;8:e20

22. Sgouros S, Goldin JH, Hockley AD, Wake MJ, Natarajan K. Intracranial volume change in childhood. J Neurosurg. 1999;91:610-6.

23. Toma R, Greensmith AL, Meara JG, Da Costa AC, Ellis LA, Willams SK, Holmes AD. Quantitative morphometric outcomes following the Melbourne method of total vault remodeling for scaphocephaly. J Craniofac Surg. 2010;21:637-43.

24. Meyer-Marcotty P, Bohm H, Linz C, Kochel J, Stellzig-Eisenhauer A, Schweitzer T. Three-dimensional analysis of cranial growth from 6 to 12 months of age. Eur J Orthod. 2014;36:489-96.

25. Seeberger R, Hoffmann J, Freudlsperger C, Berger M, Bodem J, Horn D, Engel M. Intracranial volume (ICV) in isolated sagittal craniosynostosis measured by 3D photocephalometry: a new perspective on a controversial issue. J Craniomaxillofac Surg. 2016:44:626-31.

26. Babyak MA. What you see may not be what you get: a brief, nontechnical introduction to overfitting in regression-type models. Psychosom Med. 2004;66:411-21.
27. Rothman KJ. Epidemiology - an introduction. Toronto: Oxford University Press; 2012. p. 226

28. Dekaban AS. Tables of cranial and orbital measurements, cranial volume, and derived indexes in males and females from 7 days to 20 years of age. Ann Neurol. 1977;2:485-91.

29. Vannucci RC, Barron TF, Lerro D, Anton SC, Vannucci SJ. Craniometric measures during development using MRI. Neurolmage. 2011;56:1855-64.

30. Bergerhoff W. Determination of cranial capacity from the roentgenogram. Fortschr Geb Rontgenstr Nuklearmed. 1957;87:176-84.

31. Slovis T. Anatomy of the skull. 11th ed. Amsterdam: Mosby Elsevier; 2007.

32. Cooke R, Lucas A, Yudkin P, Pryse-Davies J. Head circumference as an index of brain weight in the fetus and newborn. Early Hum Dev. 1977;1:145-9.

33. Lindley A, Benson J, Grimes C, Cole T, Herman A. The relationship in neonates between clinically measured head circumference and brain volume estimated from head CT-scans. Early Hum Dev. 1999:56:17-29.

34. Bruner E. Geometric morphometrics and paleoneurology: brain shape evolution in the genus homo. J Hum Evol. 2004:47:279-303.

35. Holloway RL. The evolution of the primate brain: some aspects of quantitative relations. Brain Res. 1968;7:121-72.

36. Howells WW. Howells' craniometric data on the internet. Am J Phys Anthropol. 1996;101:441-2.

37. Buda FB, Reed JC, Rabe EF. Skull volume in infants. Methodology, normal values, and application. Am J Dis Child. 1975;129:1171-4.

38. Scheffler $\mathrm{C}$, Greil $\mathrm{H}$, Hermanussen M. The association between weight, height, and head circumference reconsidered. Pediatr Res. 2017. :https://doi. org/10.1038/pr.2017.3

39. Kolar JC, Munro IR, Farkas LG. Patterns of dysmorphology in Crouzon syndrome: an anthropometric study. Cleft Palate J. 1988;25:235-44.

40. Rijken BF, den Ottelander BK, van Veelen ML, Lequin MH, Mathijssen IM. The occipitofrontal circumference: reliable prediction of the intracranial volume in children with syndromic and complex craniosynostosis. Neurosurg Focus. 2015:38:E9.

41. Fischer S, Maltese G, Tarnow P, Wikberg E, Bernhardt P, Tovetjarn R, Kolby L. Intracranial volume is normal in infants with sagittal synostosis. J Plast Surg Hand Surg. 2015;49:62-4.

42. Lichtenberg R. Radiographie du crâne de 226 enfants normaux de la naissance à 8 ans: Impressions digtiformes, capacite; angles et indices, Thèse pour le Doctorat en médicine. Paris: University of Paris; 1960.

43. Menichini $G$, Ruiu A. On the radiological evaluation of the cranial capacity in infants. Minerva Pediatr. 1960;12:1358-63.

44. Mackinnon IL, Kennedy JA, Davis TV. The estimation of skull capacity from roentgenologic measurements. Am J Roentgenol Radium Therapy, Nucl Med. 1956:76:303-10.

45. Lavelle CL. Craniofacial growth in patients with craniosynostosis. Acta Anat (Basel). 1985;123:201-6.

46. Tng TT, Chan TC, Hagg U, Cooke MS. Validity of cephalometric landmarks. An experimental study on human skulls. Eur J Orthod. 1994;16:110-20.

47. Ward RE, Jamison PL. Measurement precision and reliability in craniofacial anthropometry: implications and suggestions for clinical applications. J Craniofac Genet Dev Biol. 1991;11:156-64

48. Nellhaus $\mathrm{G}$. Head circumference in children with idiopathic hypopituitarism. Pediatrics. 1968;42:210-1.

49. Schweitzer T, Bohm H, Linz C, Jager B, Gerstl L, Kunz F, Stellzig-Eisenhauer A Ernestus RI, Krauss J, Meyer-Marcotty P. Three-dimensional analysis of positional plagiocephaly before and after molding helmet therapy in comparison to normal head growth. Childs Nerv Syst. 2013;29:1155-61.

50. Posnick JC, Bite U, Nakano P, Davis J, Armstrong D. Indirect intracranial volume measurements using CT scans: clinical applications for craniosynostosis. Plast Reconstr Surg. 1992;89:34-45.

51. Gault DT, Renier D, Marchac D, Ackland FM, Jones BM. Intracranial volume in children with craniosynostosis. J Craniofac Surg. 1990;1:1-3.

52. Netherway DJ, Abbott AH, Anderson PJ, David DJ. Intracranial volume in patients with nonsyndromal craniosynostosis. J Neurosurg. 2005;103: 137-41.

53. Tenhagen M, Bruse JL, Rodriguez-Florez N, Angullia F, Borghi A, Koudstaal MJ, Schievano S, Jeelani O, Dunaway D. Three-dimensional handheld scanning to quantify head-shape changes in spring-assisted surgery for Sagittal Craniosynostosis. J Craniofac Surg. 2016;27:2117-23.

54. van Lindert EJ, Siepel FJ, Delye H, Ettema AM, Berge SJ, Maal TJ, Borstlap WA. Validation of cephalic index measurements in scaphocephaly. Childs Nerv Syst. 2013;29:1007-14. 
55. Gosain AK, McCarthy JG, Glatt P, Staffenberg D, Hoffmann RG. A study of intracranial volume in Apert syndrome. Plast Reconstr Surg. 1995;95:284-95.

56. Manjunath KY. Estimation of cranial volume: an overview of methodologies. J Anat Soc India. 2002;51:85-91.

57. Steele DG, Bramblett CA. The anatomy and biology oft he human skeleton. Texas: A\&M University Press; 2007.

58. Farkas LG. Anthropometry of the head and face in medicine. New York: Elsevier; 1981.

59. McKay DR, Davidge KM, Williams SK, Ellis LA, Chong DK, Teixeira RP, Greensmith AL, Holmes AD. Measuring cranial vault volume with threedimensional photography: a method of measurement comparable to the gold standard. J Craniofac Surg. 2010;21:1419-22.

60. Hou HD, Liu M, Gong KR, Shao G, Zhang CY. Growth of the skull in young children in Baotou, China. Childs Nerv Syst. 2014;30:1511-5.

61. Christofides EA, Steinmann ME. A novel anthropometric chart for craniofacial surgery. J Craniofac Surg. 2010;21:352-7.

62. Kastellec JP, Leoni EL. Using graphs instead of tables in political science. Perspectives on Politics. 2007;5:755-71.

Submit your next manuscript to BioMed Central and we will help you at every step:

- We accept pre-submission inquiries

- Our selector tool helps you to find the most relevant journal

- We provide round the clock customer support

- Convenient online submission

- Thorough peer review

- Inclusion in PubMed and all major indexing services

- Maximum visibility for your research

Submit your manuscript at www.biomedcentral.com/submit
Biomed Central 